\title{
Islam Translated: Literature, Conversion and the Arabic Cosmopolis of South and Southeast Asia, by Ronit Ricci
}

South Asia Across the Disciplines | Chicago: University of Chicago Press, 201 I | xxii + 31 3 pages | ISBN 978-0-226-710884 (hardback) \$45.00

In her trail-blazing, multi-faceted, and illuminating

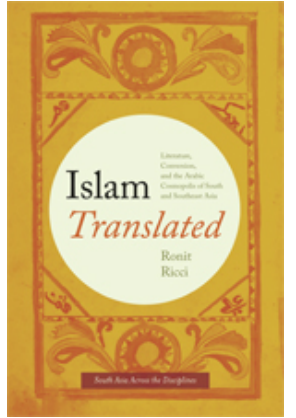
work, Islam Translated: Literature, Conversion and the Arabic Cosmopolis of South and Southeast Asia, Ronit Ricci documents the diverse forms of an important Islamic didactic text, the Book of One Thousand Questions, in South and Southeast Asia. Specifically, Ricci focuses on 
the Tamil linguistic region of Southeast India, Sumatra, and Java, with reference to other areas of the Indonesian-Malay archipelago, as well as to Sri Lanka; she looks at the historical connections between these areas, and explores the processes of transmission of the text in the pre-modern era. Dominant "tellings" (2 I, following Ramanujan) present "one thousand questions" posed by the wise Jewish leader Abdullah Ibnu Salam to the Prophet Muhammad, the Prophet's replies to the questions, and Ibnu Salam's subsequent conversion to Islam. The text is thus important for its Islamicinformational content as well as for its depiction of the Prophet and the model of conversion of the "Other" that it presents.

Ricci documents the story's background, including its roots in the Qur'an, hadith, and early sīra literature, its first mention as an independent Arabic text in the tenth century CE (35), and subsequent Latin (I 2th c.), European, and Persian translations. The focus of Ricci's study is on more recent Tamil, Javanese, and Malay translations of the text. Drawing on the South Asianist and Sanskritist Sheldon Pollock's notion of the Sanskrit "cosmopolis" and the Southeast Asianist and linguist A. L. Becker's notion of "prior text," Ricci asserts the crucial role of the One Thousand Questions text in historical conversions to Islam in South and Southeast Asia, and in the formation of an Arabic/Islamic cosmopolis in this global region. She proposes the utility of the notion of "literary networks," comprised of shared texts, and all those who participate in their generation and reception, for understanding of historical processes of Islamization.

Following the introduction (chapter I), the book is organized into two main parts: in part I, "Translation," Ricci first addresses theoretical issues related to translation, and discusses the historical background of the Book of One Thousand Questions (chapter 2). The next three chapters discuss the Javanese, Tamil, and Malaysian versions of the text, respectively. In part 2, "Conversion," Ricci first discusses Arabic in its various manifestations and functions in Javanese, Tamil, and Malay societies (chapter 6). In chapter 7 , she discusses conversion as represented in One Thousand Questions tellings and from a comparative literary perspective, drawing on other South and Southeast Asian Islamic materials. In chapter 8, Ricci tackles the intriguing question of how the image of "the Jew" functions in South and Southeast Asian societies, and examines the images of Abdullah Ibnu Salam and the Prophet in Tamil, Javanese, and Malaysian One Thousand Questions tellings. Finally, in chapter 9, Ricci ties together themes of translation, literary networks, and the Arabic cosmopolis. 
Ricci's presentation is ambitious in scope and extraordinarily rich in descriptive detail and nuanced historical and theoretical considerations. Much of the historical and descriptive material is completely new, and it alone makes a valuable contribution to comparative literary, religious/Islamic studies and South and Southeast Asian studies fields. A brief review cannot hope to do justice to a work of this scope and complexity, or to Ricci's prodigious effort. The following remarks address larger issues and themes of the content of the study, and one very basic issue of scholarly ethics.

Ricci affirms that the focus of her study is on the role of Arabic in the Islamization of the South and Southeast Asian region. She looks closely at very specific ways in which the Arabic language and script are deployed in these cultures - from the micro-level of writing systems and scripts to the macro-levels of normative discursive traditions and political rule- and argues that Arabicization is fundamentally transformative for these cultures. The discussion is enlightening, but a few critical remarks are in order.

First, while One Thousand Questions texts go back to Arabic original sources, the earliest independent text of the story Ricci has uncovered is in Arabic, and numerous extant texts are apparently based on Arabic originals, still, two of the three South/Southeast Asian One Thousand Questions texts Ricci selects for close study and discussion in Chapters 3-5 are, by her account, based on Persian originals. Ricci is not actually looking at Arabic influence in these cases that are central to her study. Given longstanding independent Persianate civilizational traditions and historical distinctions between Arabicand Persian-centered Islamic traditions (and the plausibility of a "Persian cosmopolis" concept), the logic of the analysis is problematic. Additional theorizing of the relationship between Arabic and Persian texts, literary networks, and civilizational traditions would strengthen the analysis.

Second, Ricci's presentation of Islamic perceptions of Arabic glosses over distinctions between Qur'anic Arabic and more mundane uses of the language. It is true that Arabic is regarded differently in lands distant from the Arabic-speaking homeland of Islam than it is in lands where one "does the shopping," so to speak, in Arabic; in South and Southeast Asia it is exotic for many, and authoritative for all; it is an identity-marker, and as a religious language it is understood as sacred even beyond the Qur'anic context. Still, Ricci's move from, "For Muslims worldwide Arabic possesses a unique status among languages. It is considered the perfect tongue, in which God's divine decrees were communicated to His Prophet" to "Consequently, at least ideally, it [Arabic] is considered untranslatable," (I4) is problematic. This 
shift enables what becomes a kind of mechanical understanding of the role of Arabic in historical transformation of the region in Ricci's larger analysis. But language use is a human phenomenon, and Arabic is, in many ways, a language like any other. Here, as elsewhere in the volume, a focus on humans and human agency, and an empirical, social scientific perspective would temper text- and language-focused observations of an abstract, theoretical nature. This is more a shift in emphasis and perspective than anything else, but would be a salutary corrective.

Third, and on a related issue, in framing her study, Ricci carefully avoids the pitfall of assuming that a purely textual analysis suffices to explain the literary legacy or to explain Islamization in the region: "overlap and interaction between written and oral forms of production mean that any discussion of cultural or religious transmission in South and Southeast Asia must remain keenly aware of its non-inscribed aspects. My own focus here, however, is on the circulation of written works." (2) Despite this nuanced view, this reader's sense is that Ricci's study, with its focus on texts and, generally, the production-side of literary networks, tends to operate at such a level of abstraction from human realities and agency, as well as from audiences and receptive contexts, that analysis of both the One Thousand Questions texts and their historical impact, and the broader phenomenon of "Islamization" are handicapped, or partial at best. Of course, one must also acknowledge and make allowances for the difficulty of documenting histories of performance and reception for the time periods and regions of Ricci's study. This is an arena in which contemporary local Islamic traditions of scholarship on their own literary traditions offer little or no assistance.

Fourth, Ricci makes ambitious claims for the role of Arabic language and literature in historical processes of conversion and Islamization, which begs the question of their impact relative to other factors-many of which have been discussed extensively in extant scholarship. This writer would suggest that "Islamization" is a broader cultural process than Ricci's theory of Arabicization (or any necessarily "elites down" linguistic and literary theory of historical process), alone, can explain. On the positive side, Ricci's analysis focusing on text, translation and literary networks reminds modern readers who might tend to take literacy, literary production and basic religious texts for granted, to appreciate the enormity of this cultural project and the sustained effort it entails-especially on civilizational and linguistic frontiers, and especially in the premodern era. 
Fifth, Becker's notion of "prior text" is an interesting choice of theoretical perspective, and seems to be a step in the right direction, in terms of understanding the history of the One Thousand Questions text in the South and Southeast Asian region as well as in contributing to understandings of processes of Islamization and conversion in the region. The strength of the analytical framework Ricci adopts is that it is processual, it aims to provide a key to understanding the dynamics of cultural and religious change over time, and, as in educational/cognitive development theory, it recognizes the importance of prior ways of knowing for the creation of new knowledge and social memory. The disadvantage of Becker's theory (as Ricci presents it) is its assumption that "text" and discursive knowledge encompass all knowing, and can fully explain social memory. Ricci avoids this pitfall, in her most focused statements regarding her project's aims and limitations. At other times, she seems to fall in with Becker's assumptions about the universal applicability of "text" and its historical instrumentality and explanatory power; in any case, she does not critique the model he proposes. This is curious, since scholarly critique of the preoccupation with "text"-both as artifact and as metaphor-in religious studies scholarship has been around for some time and has made important contributions to our understanding of human religious experience. ${ }^{2}$ Becker's theory of the importance of "prior texts" for individual and socio-cultural processes of knowing, as Ricci presents it, is not adequate as an holistic explanation of Islamization since it does not take non-discursive, non-representational, non-symbolic ways of knowing into account. (This goes beyond acknowledgement of the importance of performative contexts, of oral and aural aspects of texts, and of contexts of reception and audience response to texts.) For powerful new advances in the study of "Islamization" in this world region and beyond, this writer's sense is that what is needed is a theory that can integrate textual, symbolic, discursive and non-textual, bodily, and ritual/performative aspects of social memory. Absent such a theory, the combined contributions of literary, historical, and social scientific modes of research and analysis is no doubt greater than the individual contributions of any single theoretical perspective.

This is an ambitious project, and Ricci's grasp of the variety of languages and knowledge of the diverse cultural realms involved in the study is ex-

${ }^{2}$ An influential essay by Lawrence E. Sullivan comes to mind ("Seeking an End to the Primary Text or Putting an End to the Text as Primary", in Beyond the Classics: Essays in Religious Studies and Liberal Education, ed. Frank E. Reynolds and Sheryl Burkhalter (Atlanta: Scholars Press, I990), 4I-59). 
traordinary. It is worth noting, however, that Ricci presents translations of selected passages, only, of the One Thousand Questions texts she considers and it is not evident that she has read or translated the primary works in their entirety. This is perhaps understandable, given the overall scope, difficulty, and aims of her project. Nonetheless, more direct translation would be welcome, especially given what Ricci reveals of the fascinating, often Sufism-oriented content of what otherwise might be assumed to be straightforward didactic works. (This didactic literature is very different from today's "pamphlet Islam", to use Omid Safi's expression. ${ }^{3}$ )

Given the relative lack of Western scholarship on the Tamil and Southeast Asian Islamic literary traditions (in comparison to North Indian Urdu linguistic and cultural traditions, for example), the ambitious nature of Ricci's project, and, in the Tamil case, at least, the extensive work by Tamil Muslim scholars on Islamic Tamil literary traditions, exploration of and reference to local scholarly work is not only understandable, but important-in fact, for this writer, essential. Furthermore, post-colonial, cross-cultural, scholarly ethics demand total transparency regarding reference to and use of local scholarly sources and resources, as well as truly collaborative work across international, cultural (and economic) lines. Such transparency might well serve to inject a spirit of sanity and realistic expectations into the scholarly enterprise, as well.

Ricci has clearly worked intensively with the Tamil original text, and she acknowledges her debt to Takkalai M.S. Basheer, a scholar of Tamil literature in Chennai ("Madras," xiii), for discussing Tamil texts with her, for example. But significant aspects of her chapter on the Tamil One Thousand Questions text, the Ayira Macalä, evidently rely, without citation, on an important Tamil secondary source, M. M. Uwise and P. M. Ajmal Khan's $I_{s-}$ làmiyat Tamil Ilakkiya Varaläru ("Islamic Tamil Literary History"), ${ }^{4}$ in the sense of summarizing parts of the chapter on the Ayira Macalä (vol. I, ch.4) and, apparently, using it as a guide to important themes and a pointer to important passages in the primary One Thousand Questions text. Ricci does refer to another volume of the work with regard to other Tamil literary works, and the four-volume work as a whole does appear in the bibliography, but she does not cite Uwise and Ajmal Khan's chapter on the Äyira Macalā anywhere

${ }^{3}$ Omid Safi, “Introduction: The Times They Are A Changin'-A Muslim Quest for Justice, Gender Equality and Pluralism", in Progressive Muslims: On Justice, Gender and Pluralism, ed. Omid Safi (New York: Oneworld, 2003), $22 \mathrm{ff}$.

${ }^{4} 4$ vols. Maturai: Kāmarācar Palkalai Kalakam, I986-I997. 
in her chapter on the Tamil One Thousand Questions text. The lack of citation may be a simple oversight which would be understandable in a work of this scope, but it is a significant omission, which one hopes will be corrected in future printings of the book. On a related point, the statement that M. M. Uwise's Tamililakkiya Arapuccol Akaräti is "the best study of Muslim Tamil literature to date" (59n70), is incorrect and possibly misleading. The Tamililakkiya Arapuccol Akarāti is simply an Arabic-Tamil dictionary. The best study of Islamic Tamil literature to date is the four-volume Islamiyat Tamil Ilakkiya Varalāru ("Islamic Tamil Literary History") mentioned above, coauthored by Professors Uwise and Ajmal Khan. Both the dictionary and the literary survey will be useful to scholars who wish to pursue research in the Islamic Tamil Studies field.

These critical remarks notwithstanding, Ricci's work invites appreciation and development on many fronts and from many disciplinary perspectives. Ricci's documentation of the breadth of dispersion of One Thousand Questions tellings, from the UK to the Moluccas, is impressive-one imagines that additional evidence of the textual corpus and its legacy will be found in East and West Africa, Central Asia, and China. Perhaps scholars focusing on these world regions will assist in filling out the global history of this important Islamic text. More work on the One Thousand Questions tellings themselves, including more direct translation, would be valuable. The Persian history of the One Thousand Questions text deserves attention. Various facets of Tamil, Malaysian, and Indonesian Islamic realms invite further study, and Ricci has provided important guideposts for such study. As far as conversion and Islamization are concerned, Ricci's study gives a certain purchase on the roles of Arabic language, literature and literary cultures, and networks in the process. One might try to apply her theoretical insights and the "Arabic cosmopolis" concept retrospectively, to the Arab-Islamic-Persian cultural encounter, as well as to new Islamic frontier zones-emerging Muslim worlds in the United States, Europe and Australia, for example. As Michael Muhammad Knight's novel (2004) and film (2010), The Taqwacores, brilliantly demonstrate for the US context, one might expect to see both the relevance and applicability of the "Arabic cosmopolis" historical-linguistic concept, as well as its limitations, in terms of explaining processes of "Islamization."

Susan Schomburg

Lewiston, Maine 